\title{
Serological Detection of Helicobacter pylori Antibodies in Patients Suffering from Gastric Symptoms in Kano, Nigeria
}

\author{
Abdulhadi Sale Kumurya \\ Department of Medical Laboratory Science, Faculty of Allied Health Sciences, Bayero University, Kano, Nigeria \\ Email address: \\ askumurya.med@buk.edu.ng (A. S. Kumurya)

\section{To cite this article:} \\ Abdulhadi Sale Kumurya. Serological Detection of Helicobacter pylori Antibodies in Patients Suffering from Gastric Symptoms in Kano, \\ Nigeria. American Journal of Health Research. Vol. 3, No. 6, 2015, pp. 352-355. doi: 10.11648/j.ajhr.20150306.16
}

\begin{abstract}
Background: Helicobacter pylori is a major gastroduodenal pathogen and its seropositivity is associated with increased risk of development of human active chronic gastritis, peptic and duodenal ulcer and gastric cancer. Objectives: The aim of this study was to determine the seroprevalence of $H$. pylori infection among subjects with gastrointestinal problems. Methods: From May 2014 to October 2014, a seroprevalence study was carried out among 100 subjects who had clinical gastric symptoms, with a mean age of 37.77 years (range, 2 to 70 years). Serum samples collected from 44 male and 56 female were screened for detection of anti $H$. pylori IgG using commercial DIAQUICK Helicobacter pylori (manufactured by DIALAB Production, GMBH) kit. Statistical analyses were performed using SAS software, version 9.1 (SAS Institute Inc., Cary, NC). Results: The overall seropositivity rate of anti $H$. pylori IgG was 53\%. Seropositivity of anti $H$. pylori IgG increased markedly with age and highest infection rate (96\%) was seen in individuals 40 to 50 years old. Anti $H$. pylori IgA was also correlated with increasing age. Analysis of results for gender showed that there were no significant differences in seropositivity to $H$. pylori between men and woman $(\mathrm{p}>0.05)$ but there was a significant correlation between anti $H$. pylori $\mathrm{IgG}$ and age of subjects $(\mathrm{p}<0.01)$. Analysis of results for inflammatory markers (WBC and ESR) showed normal mean of WBC count $(7000$ cells $/ \mathrm{ml})$ and ESR rate $(8 \mathrm{~mm} / \mathrm{h})$ levels in these subjects. No association was detected between $H$. pylori seropositivity, gender and inflammatory laboratory parameters. Conclusion: This study revealed the high prevalence of $H$. pylori infection among symptomatic subjects in the study area suggesting necessity of screening for $H$. pylori infection in symptomatic patients. The results also did not show any strict relations between $H$. pylori seropositivity, gender and inflammatory markers.
\end{abstract}

Keywords: Helicobacter pylori, Seroprevalence, IgG, Gastritis, Nigeria

\section{Introduction}

Helicobacter pylori is the most common cause of chronic gastritis, infecting more than half of the world's population (Torres et al., 2000). It is implicated in the etiology of a variety of gastrointestinal diseases, including duodenal ulcer, nonulcer dyspepsia and active and chronic gastritis (Marshall et al., 1985; Soll, 1990). This bacterium is also associated with a variety of disease ranging from asymptomatic gastritis to severe gastric ulcer which can progress to a gastric malignancy. Numerous reports have confirmed an association between the presence of $H$. pylori on the gastric mucosa of patients and increased risk for gastric carcinoma (Peterson et al., 2000; Suerbaum and Michetti, 2002). Several seroepidemiological study have shown that the presence of serum IgG antibodies to $H$. pylori is related to an increased risk for developing peptic disease and duodenal ulcer (Peterson et al., 2000; Gdalevich et al., 2000) hence, detection of antibodies is a critical step in management and prevention of serious outcomes and complication of $H$. pylori infection. The seroprevalence of $H$. pylori has been studied in healthy subjects and asymptomatic populations by chromatographic immunoassays, in both developed and developing countries (Best et al., 1994; Lindkvist et al., 1996) and high infection rates have been reported from developing countries (Torres et al., 2000). Moreover, several studies have shown a wide variation in the prevalence of $H$. pylori antibodies among age groups in different geographical regions (Atalay et al., 2003). No local studies are available regarding seroprevalence of $H$. pylori infection in North-western Nigeria. Measurement of serum immunoglobulin $\mathrm{G}$ ( $\mathrm{IgG})$ antibodies to $H$. pylori can be used to determine the prevalence of the infection. This study 
was conducted to evaluate the seroprevalence of $H$. pylori infection among symptomatic subjects using rapid immunochromatographic method to determine anti H. pylori IgG.

\section{Materials and Methods}

\subsection{Study Population}

From May 2014 to October 2014, a seroprevalence study was carried out among 100 subjects who had clinical gastric symptoms, with a mean age of 37.77 years (range, 2 to 70 years). All patients had blood drawn for serological testing at the time of attending in Decent Medical laboratories, Kano, Nigeria. After collection, the serum was separated, aliquoted and frozen at $-20^{\circ} \mathrm{C}$ until being tested. Demographic data including age and gender as well as Laboratory parameters such as WBC (White blood cell) and ESR (Erythrocyte sedimentation rate) were analysed in all subjects.

\subsection{Rapid Chromatographic Immunoassay}

Rapid chromatographic immunoassay was used for the qualitative detection of antibodies (IgG) to H. pylori in serum samples, according to previously reported methods (Jafarzadeh et al., 2007). Assays were performed by a commercial DIAQUICK Helicobacter pylori kit, (manufactured by DIALAB Production, GMBH) following the manufacturer's instructions. Conditions were the same for all assays. Serum was separated from blood as soon as possible to avoid hemolysis. All the test samples, kits, buffer and controls were allowed to reach room temperature (15$30^{\circ} \mathrm{C}$ ) prior to testing. Approximately $100 \mu \mathrm{l}$ of each test samples were transferred to the specimen wells of the test cassette. Results were read at 10 minutes. All equivocal results were repeated.

\subsection{Statistics}

Statistical analyses were performed using SAS software, version 9.1 (SAS Institute Inc., Cary, NC). p-value of 0.05 or less was regarded as statistically significant.

\section{Results}

This study was performed in 100 subjects with gastric symptoms, including 56 female and 44 male with an age range of 2 to 70 years (mean age 37.77 years). All subjects were from Kano, Northwestern Nigeria.

\subsection{Diagnosis of H. pylori by Serological Tests}

Among 100 serum specimens tested for anti H. pylori $\mathrm{IgG}$, $53(53 \%)$ were positive and $47(47 \%)$ were negative (Table 1$)$.

\subsection{Correlation of Age and Sex with Seropositivity of $H$. pylori}

Screening for anti $H$. pylori IgG revealed that 53 (53\%) subjects were positive and $47(47 \%)$ was negative. Analysis of results for gender showed that there were no significant differences in seropositivity to $H$. pylori between men and woman $(\mathrm{p}>0.05)$ but there was a significant correlation between anti $H$. pylori $\operatorname{IgG}$ and age of subjects $(\mathrm{p}<0.01)$. The rate of IgG seropositivity increased markedly with age, being maximum $(45.2 \%)$ in 30 to 50 years old age group. After that, there was a small and steady decrease between age 50 and 60 , but a slight arise was seen above 60 years old as shown in Table 2. Analysis of results for inflammatory markers (WBC and ESR) showed normal mean of WBC count $(7000$ cells $/ \mathrm{ml})$ and ESR rate $(8 \mathrm{~mm} / \mathrm{h})$ levels in these subjects. This study revealed no significant correlation between inflammatory markers and seroprevalence of $H$. pylori infection.

Table 1. Distribution of H. pylori IgG among subjects with gastric symptoms based on gender $(n=100)$.

\begin{tabular}{l|lll}
\hline \multicolumn{4}{l}{ Subjects with gastric symptoms (\%) } \\
\hline Sex & $\begin{array}{l}\text { H. pylori IgG } \\
\text { Positive (\%) }\end{array}$ & $\begin{array}{l}\text { H. pylori IgG } \\
\text { Negative (\%) }\end{array}$ & Total \\
\hline Male & $23(52.3)$ & $21(47.7)$ & $44(44.0)$ \\
Female & $30(53.6)$ & $26(46.4)$ & $56(56.0)$ \\
Total & $53(53.0)$ & $47(47.0)$ & $100(100)$ \\
\hline
\end{tabular}

$\mathrm{p}>0.05$

Table 2. Distribution of immunoglobulin (IgG) antibodies to H. pylori in 53 subjects in different age groups.

\begin{tabular}{llll}
\hline Age groups (years) & Male & Female & Total \\
\hline $0-10$ & $0(00.0)$ & $1(3.3)$ & $1(1.9)$ \\
$11-20$ & $1(4.3)$ & $2(6.7)$ & $3(5.7)$ \\
$21-30$ & $2(8.7)$ & $3(10.0)$ & $5(9.4)$ \\
$31-40$ & $4(17.4)$ & $5(16.7)$ & $9(16.9)$ \\
$41-50$ & $7(30.4)$ & $8(26.7)$ & $15(28.3)$ \\
$51-60$ & $3(13.0)$ & $4(13.3)$ & $7(13.2)$ \\
$61-70$ & $6(26.1)$ & $7(23.3)$ & $13(24.5)$ \\
Total & $23(43.4)$ & $30(56.6)$ & $53(100)$ \\
\hline
\end{tabular}

Mean age 37.77 years, $\mathrm{p}<0.01$

\section{Discussion}

H. pylori infection is an important risk factor for development severe gastric problems (Malekzadeh et al., 2009). Detection of $H$. pylori infection with non-invasive methods such as serological tests are useful, widely available and inexpensive (Ricci et al., 2007). These methods contribute an advantage to epidemiological research in which typically large numbers of subjects can be studied from easily obtained blood samples. The results of this study showed that the overall seroprevalence of $H$. pylori infection based on anti $H$. pylori IgG was $53 \%$. This result indicated that our seroprevalence is higher than many developed countries reported as 37\% in United States (Graham et al., 1991) and $40 \%$ in Germany (Seher et al., 2000) but lower than some developing countries reported as, $90 \%$ in Bangladesh (Mahalanabis et al., 1996). It has been reported that IgG titre indicates chronic infection. Our result revealed an age-related increase of anti $H$. pylori IgG. The seropositivity of IgG varied in different age group, from $1.9 \%$ in 0 to 10 years old group to $24.5 \%$ in the age group of 60 to 70 years. In 
addition there was a slight decrease in the seropositivity of IgG over 50 years of age in our study, similar to results reported by Kate et al. (2001), and this may be related to eradication of the bacterium due to potentiation of immune response. The age-related increase in antibody prevalence in the present study was similar to results of previously published studies. In a study carried out in Southeastern Nigeria with 1,206 ulcer patients confirmed positive by faecal occult blood test, $703(58 \%)$ were positive for $\mathrm{H}$. pylori IgG antibody serological test (Ifeanyi O. C. O and Prosper O. U. A, 2013). Another study in South-western Nigeria with 185 children tested for $H$. pylori antigen found $134(68.7 \%)$ and $51(26.2 \%)$ as seropositive and fecal HpSA positive respectively (Olufemi et al., 2015).

A study conducted in southern of Iran (Shiraz) revealed that $82 \%$ of children aged nine months and $98 \%$ of two year old children were $H$. pylori infected (Alborzi et al., 2006). Also in Rafsanjan, another city of Iran, high infection rate of H. pylori in children and adults and its correlation with age has also been reported (Jafarzadeh et al., 2007).This result also is in accord with many reports from other countries (Gisbert et al., 2001; Gill et al., 1994). A study by Fock (1997) showed that seroprevalence of $H$. pylori infection in Singapore increases with age from $3 \%$ in children under 5 years old up to $71 \%$ in adults above 65 years. The age-related increase of seroprevalence is attributable to the fact that $H$. pylori infection is usually acquired during childhood and carried for life. This study also demonstrated that gender had no influence on $H$. pylori infection rate. A number of other studies have yielded similar results and shown no significant correlation between $H$. pylori infection and gender (JimenezGuerra et al., 2000). However, there are few studies reported a significant association of $H$. pylori infection with male gender (Leandro et al., 2005). The results from this study, although indicated that inflammatory marker such as WBC (white blood cell) and ESR (erythrocyte sedimentation rate) were not correlated with seropositivity of $H$. pylori infection.

\section{Conclusion}

The results of this study showed high prevalence of $H$. pylori IgG antibodies in patients suffering from gastric symptoms suggesting necessity of screening for $H$. pylori infection in symptomatic patients. This result also did not show any strict relations between $H$. pylori seropositivity, gender and inflammatory markers.

\section{References}

[1] Alborzi A, Soltani J, Pourabbas B, Oboodi B, Haghighat M, Hayati M, Rashidi M (2006). Prevalence of Helicobacter pylori infection in children (south of Iran). Diagn. Microbiol. Infect. Dis. 54: 259-261.

[2] Atalay C, Atalay G, Altinok M (2003). Serum Helicobacter pylori IgG and IgA levels in patients with gastric cancer.Neoplasma50: 185-190.
[3] Best LM, Veldhuyzen van Zanten SJ, Sherman PM, Bezanson GS (1994). Serological detection of Helicobacter pylori antibodies in children and their parents. J. Clin. Microbiol.32(5): 1193-1196.

[4] Fock KM (1997). Helicobacter pylori infection - Current status in Singapore. Ann. Acad. Med. Singapore 26(5): 637-641.

[5] Gdalevich M, Cohen D, Ashkenazi I, Mimouni D, Shpilberg O, Kark JD (2000). Helicobacter pylori infection and subsequent peptic duodenal disease among young adults. Int. J. Epidemiol. 29: 592-595.

[6] Gill HH, Majmudar P, Shankaran K, Desai HG (1994). Agerelated prevalence of Helicobacter pylori antibodies in Indian subjects. Indian J. Gastroenterol.13: 92-94.

[7] Gisbert JP, Pajares JM (2001). Diagnosis of Helicobacter pylori infection by stool antigen determination: A systematic review. Am. J. Gastroenterol. 96: 2829-2838.

[8] Graham DY, Malaty HM, Evans DG, Evans DJ, Klein PD, Adam E (1991). Epidemiology of Helicobacter pylori in an asymptomatic population in the United States: Effect on age, race, and socioeconomic status. Gastroenterology100: 14951501 .

[9] Ifeanyi OCO and Prosper OUA (2013). Prevalence of Helicobacter pylori and other intestinal parasites amongst duodenal and gastric ulcer patients at Imo state University Teaching Hospital, Orlu, South-eastern Nigeria. Journal of Medicine and Medical Sciences. 4(9): 362-369 Available online http://www.interesjournals.org/JMMS.

[10] Jafarzadeh A, Rezayati MT, Nemati M (2007).Specific serum immunoglobulin $\mathrm{G}$ to $\mathrm{H}$. pylori and CagA in healthy children and adults (south-east of Iran).World J. Gastroenterol.13: 3117-3121.

[11] Jimenez-Guerra F, Shetty P, Kurpad A (2000).Prevalence of and risk factors for helicobacter pylori infection in school children in Mexico.Ann. Epidemiol. 10: 474.

[12] Kate V, Ananthakrishnan N, Ratnakar C, Badrinath S (2001). Anti - H. pylori IgG seroprevalence rates in asymptomatic children and adults from South India. Indian J. Med. Microbiol.19: 20-25.

[13] Leandro Liberato SV, Hernndez Galindo M, Torroba Alvarez L, SmezAbada A, ChuecaRodrguez P (2005). Helicobacter pylori infection in the child population in Spain: Prevalence, related factors and influence on growth. An. Pediatr. (Barc) 63: 489-494.

[14] Lindkvist P, Asrat D, Nilsson I, Tsega E, Olsson GL, Wretlind B, Giesecke J (1996). Age at acquisition of Helicobacter pylori infection: Comparison of a high and a low prevalence country. Scand. J. Infect. Dis.28: 181-184.

[15] Mahalanabis D, Rahman MM, Sarker SA, Bardhan PK, Hildebrand P, Beglinger C, Gyr K (1996). Helicobacter pylori infection in the young in Bangladesh: Prevalence, socioeconomic and nutritional aspects. Int. J. Epidemiol.25: 894-898.

[16] Malekzadeh R, Derakhshan MH, Malekzadeh Z (2009). Gastric cancer in Iran: Epidemiology and risk factors. Arch. Iran Med.12: 576-583.

[17] Marshall BJ, McGechie DB, Rogers PAR and Glancy RG (1985).Pyloric Camylobacter infection and gastroduodenal disease. Med. J Australia. 149:439-44. 
[18] Nouraie M, Latifi-Navid S, Rezvan H, Radmard AR, Maghsudlu M, Zaer-Rezaii H, Amini S, Siavoshi F, Malekzadeh R (2009). Childhood hygienic practice and family education status determine the prevalence of Helicobacter pylori infection in Iran. Helicobacter 14: 40-46.

[19] Oluwasola AO, Ola SO, Saliu L, Solanke TF (2002).Helicobacter pylori infection in South Nigerians: A serological study of dyspeptic patients and healthy individuals. West Afr. J. Med. 21: 138-141.

[20] Olufemi FO, Quadri R, Akinduti PA and Bamiro SA(2015) Potential Risk Factors and Prevalence of Infection of Helicobacter pylori in Nigeria. Journal of Scientific Research \& Reports. 7(1): 42-48.

[21] Pérez-Pérez GI, Cutler AF, Blaser MJ (1997).Value of serology as a noninvasive method for evaluating the efficacy of treatment of Helicobacter pylori infection. Clin. Infect. Dis. 25: $1038-1043$.

[22] Peterson WL, Fendrick AM, Cave DR, Peura DA,
Garabedian-Ruffalo SM, Laine L (2000) Helicobacter pylorirelated disease: Guidelines for testing and treatment. Arch. Int. Med.160: 1285-1291.

[23] Ricci C, Holton J, Vaira D (2007). Diagnosis of Helicobacter pylori: Invasive and non-invasive tests. Best Pract. Res. Clin. Gastroenterol.21: 299-313.

[24] Seher C, Thierfelder W, Dortschy R (2000). Helicobacter pylori-prevalence in the German population. Gesundheitswesen62: 598-603.

[25] Soll AH (1990). Pathogenesis of peptic ulcer and implications for therapy. New England J. Med.322:909-16.

[26] Suerbaum S, Michetti P (2002). Helicobacter pylori infection.N. Engl. J. Med. 347: 1175-1186.

[27] Torres J, Pérez-Pérez G, Goodman KJ, Atherton JC, Gold BD, Harris oz O (2000). A comprehensive review of the natural history of Helicobacter pylori infection in children. Arch. Med. Res. 31: 431-469. 